\title{
EFEKTIVITAS BIBLIOTERAPI UNTUK MENINGKATKAN KETANGGUHAN AKADEMIK SANTRI (STUDI PADA PESANTREN X, BOGOR, JAWA BARAT)
}

\author{
Ade Ubaidah ${ }^{1}$, Sri Tiatri ${ }^{2}$, dan Heni Mularsih ${ }^{3}$ \\ ${ }^{1}$ Program Studi Magister Psikologi, Universitas Tarumanagara \\ Email:ade.ubaidah123@gmail.com \\ ${ }^{2}$ Program Studi Magister Psikologi, Universitas Tarumanagara \\ Email: sri.tiatri@untar.ac.id \\ ${ }^{3}$ Program Studi Magister Psikologi, Universitas Tarumanagara \\ Email: henim@mku.untar.ac.id
}

\begin{abstract}
Bibliotherapy is a method that uses literature to help clients to be able to express the problems they face and change their thinking perspective as an effort to help them overcome emotional problems, unstable mental conditions to overcome changes in their lives. Many bibliotherapy studies reveal that bibliotherapy is effective in dealing with problems, including reducing aggressiveness in adolescents. However, researchers have not found a study of bibliotherapy improving academic resilience in adolescent students. This study aims to examine the effectiveness of bibliotherapy in improving students' academic resilience, a study of 7th grade students of SMPIT, X Islamic Boarding School, Bogor, West Java. The application of bibliotherapy was carried out on five experiment participants selected through purposive sampling, which was carried out in eleven meetings, which were divided into four stages based on the theory of the stages of bibliotherapy according to Pardeck (1993), namely identification, selection, presentation, and follow-up. The research method used was experiment, with randomized pretest-posttest control group design. Academic resilience measurement data of the control and experimental groups was processed with SPSS using the Independent Sample T-test method shows that bibliotherapy is ineffective in increasing the academic resilience of students of Islamic boarding school $(t=-, 17, p=0.87, p>0.05)$. It is suspected that one of the causes is inadequate participant involvement in the vicarious learning process during bibliotherapy.
\end{abstract}

Keywords: bibliotherapy, academic resilience, Islamic boarding school students, intervention

\begin{abstract}
ABSTRAK
Biblioterapi adalah suatu metode yang menggunakan literatur dalam membantu klien agar mampu mengungkapkan permasalahan yang dihadapinya dan mengubah cara pandang berpikirnya sebagai upaya membantunya mengatasi masalah emosi, kondisi mental yang tidak stabil untuk mengatasi perubahan dalam hidupnya. Banyak penelitian biblioterapi yang mengungkapkan bahwa biblioterapi efektif dalam mengatasi masalah, diantaranya dalam menurunkan agresivitas pada remaja. Akan tetapi, peneliti belum mendapati kajian penelitian biblioterapi untuk meningkatkan ketangguhan akademik pada siswa remaja. Penelitian ini bertujuan menguji efektivitas biblioterapi untuk meningkatkan ketangguhan akademik santri, suatu studi pada santri kelas 7 SMPIT, Pesantren X, Bogor, Jawa Barat. Penerapan biblioterapi dilakukan pada lima partisipan eksperimen yang dipilih secara purposive sampling, yang dilaksanakan dalam sebelas kali pertemuan, yang dibagi menjadi empat tahap berdasarkan teori tahapan biblioterapi menurut Pardeck (1993) yaitu identifikasi, seleksi, presentasi, dan follow-up. Metode penelitian yang digunakan adalah eksperimen, dengan randomized pretest-posttest control group design. Data pengukuran ketangguhan akademik pada kelompok kontrol dan eksperimen diolah dengan SPSS menggunakan metode Independent Sample T-test menunjukkan biblioterapi tidak efektif untuk meningkatkan ketangguhan akademik santri pesantren $(t=-, 17, p=0,87, p>0,05)$. Diduga salah satu penyebab adalah kurang memadainya keterlibatan partisipan dalam proses vicarious learning selama mengikuti biblioterapi.
\end{abstract}

Kata kunci: biblioterapi, ketangguhan akademik, santri pesantren, intervensi

\section{PENDAHULUAN Latar Belakang}


Data yang diperoleh di laman Khazanah Harian Republika Online menyatakan bahwa pada tahun 2010 terdapat 3,6 juta santri tersebar pada 27.230 pondok pesantren di 33 provinsi di Indonesia (Djibril, 19 Juli 2011, www.republika.com diunduh, 06 Desember 2017). Hal ini menunjukan bahwa menempuh pendidikan menengah pertama di pesantren adalah salah satu pilihan pendidikan Islam bagi remaja muslim di Indonesia. Pilihan menempuh pendidikan menengah pertama di Pesantren sebagai santri mengharuskan anak tinggal di asrama dengan mematuhi segala peraturan yang berlaku di pesantren tersebut.

Perpindahan pendidikan dari sekolah dasar ke sekolah menengah pertama dengan sistem asrama seperti pesantren, merupakan proses yang tidak mudah. Oleh karena menjadi santri pesantren membuatnya harus tinggal di asrama, terpisah dari keluarga. Hal ini membuatnya harus belajar mengurus diri sendiri dengan segala kebutuhan dirinya sendiri, mulai dari bangun tidur hingga tidur kembali. Ia juga harus belajar menghadapi situasi dan lingkungan sekolah yang baru sendiri seperti, menyesuaikan diri dengan guru-guru yang baru, tuntutan akademik, dan pergaulan, baik di sekolah maupun di asrama (dalam Mander, Lester, Cross, 2015). Dengan menjadi seorang santri, seorang anak harus belajar mandiri dalam mengatasi perubahan yang banyak secara bersamaan.

Di sisi lain, santri di usia remaja awal juga sedang mengalami perubahan perkembangan. Santri tersebut memasuki masa transisi perkembangan atau remaja-masa anak-anak menuju masa dewasa. Hal ini membuatnya mengalami perubahan perkembangan yang besar, baik dalam aspek fisik, kognitif, dan psikososial. Dalam aspek perkembangan psikososial, remaja menurut teori Erikson (dalam Santrock, 2011), remaja berada pada fase proses menemukan tujuan hidupnya. Sementara secara fisik, remaja mengalami pubertas, yaitu mengalami proses kematangan pada organ-organ seksualnya seiring dengan perubahan hormonal dalam dirinya yang rentan bermasalah dengan emosi dan mood. Dengan demikian, banyak perubahan yang harus dihadapi pada siswa diusia remaja dengan sekaligus menjadi seorang santri pesantren. Anderman (dalam Santrock, 2011) mengungkapkan bahwa perubahan yang banyak yang terjadi hampir secara bersamaan saat memasuki masa perkembangan remaja, membuat remaja rentan mengalami kondisi stres.

Penelitian Hystad, Eid, Laberg, Johnson, dan Bartone (2009) mengungkapkan bahwa stres akademis memiliki korelasi negatif dengan hardiness (ketangguhan), dan berkorelasi positif dengan keluhan kesehatan. Data hasil observasi dan wawancara tak terstruktur dengan salah satu pendamping asrama (musyrif) santri baru pada hari Kamis, 16 November 2017 di pesantren X menunjukan bahwa $10 \%$ dari keseluruhan santri baru mengeluhkan masalah kesehatan. Fenomena tersebut mengindikasikan para santri baru pesantren $\mathrm{X}$ yang menghadapi dan mengalami banyak perubahan situasi dan kondisi yang banyak secara bersamaan, mengalami kondisi stres. Kondisi stres yang dialami para santri dapat menurunkan ketangguhan akademik mereka dalam menjalani masa pendidikannya di pesantren.

Hasil penelitian lain yang dilakukan oleh Ahmadi, Zainalipour, dan Rahmani pada tahun (2013) (dikutip dalam Winy, Sahrani, \& Hastuti, 2017) mengemukakan bahwa ketangguhan akademik berkorelasi positif dengan prestasi akademik. Dengan demikian, ketangguhan akademik mempengaruhi performa dan hasil belajar yang optimal bagi santri. Pendidikan di pesantren $\mathrm{X}$ yang merupakan perpaduan sistem tradisional dan modern, serta memiliki pembelajaran unggulan berupa hafalan Al-qur'an (Tahfidz), menuntut santri mampu mengikuti pendidikan dalam sekolah formal dan kepesantrenan. Hal ini, membutuhkan adanya komitmen, dan kontrol diri serta keberanian para santri dalam menghadapi tantangan tuntutan menjalani pendidikan di 
Pesantren X tersebut. Ketiga aspek tersebut, komitmen, kontrol diri serta keberanian terhadap tantangan tercakup dalam ketangguhan akademik. Oleh karenanya perlu ada upaya untuk meningkatkan ketangguhan akademik para santri, sehingga kondisi rentan stress yang dihadapi mampu dipandang secara positif dan optimis, agar mereka terus tumbuh menjadi pribadi yang lebih baik. Peningkatan ketangguhan akademik ditujukan agar mendorong santri memiliki kemampuan kelola diri yang lebih baik agar mampu mengatasi kesulitan-kesulitan yang dihadapinya dalam belajar sehingga capaian belajar pun menjadi lebih optimal.

Subyek penelitian adalah remaja awal yang menjadi santri pesantren $\mathrm{X}$ yang memiliki jadwal kegiatan padat sehingga rentan mengalami stres akademik. Dengan perkembangan kemampuan kognitif santri dalam usia remaja ini pada tahap kemampuan berpikir formal operasional menjadikannya mampu untuk dapat berpikir reflektif (kritis). Akan tetapi, remaja sering kali kesulitan dalam menemukan cara mengatasi stres yang dialaminya (dalam Brenner, 1984). Peneliti memilih metode yang sering kali digunakan oleh para konselor bagi klien-klien yang membutuhkan adanya perubahan dalam cara berpikir yaitu dengan biblioterapi (Seligman dan Reichenberg, 2013) dalam upaya membantu subyek mengatasi stres dan membimbingnya mengoptimalkan kemampuan berpikir kritisnya sehingga mampu menemukan solusi dalam upaya mengatasi masalah (coping) yang dihadapi dalam menjalani tantangan pendidikan di pesantren. Pardeck (1994) memaparkan bahwa biblioterapi merujuk pada penggunaan literatur dalam membantu orang lain mengatasi masalah emosi, kondisi mental yang tidak stabil atau dalam mengatasi perubahan dalam hidupnya (dalam Abdullah, 2002). Tujuan tersebut sejalan dengan penelitian Swantic (1986) menjabarkan bahwa para siswa yang ikut dalam program biblioterapi menunjukkan adanya perbaikan pada perilaku belajar anak di kelas. Hal ini dikarenakan biblioterapi membangun kemampuan anak untuk mengenali dan memahami perubahan situasi yang berpotensi menjadi masalah baginya (Harbaugh, 1985). Dengan demikian biblioterapi meningkatkan keterampilan coping anak (Smith 1991 dalam Heath, Sheen, Leavy, Young, \& Money, 2005).

Sementara Maddi dan Kobasa (1984) menyatakan bahwa seorang dengan ketangguhan diri yang tinggi akan terdorong mengatasi masalah yang dihadapinya (coping) dengan cara mengubah situasi dari suatu peristiwa yang menekan menjadi situasi peristiwa yang tidak terlalu menekan baginya (dalam Cole, Field, \& Harris, 2004). Oleh karenanya, melalui program biblioterapi, santri dibimbing mampu berpikir kritis mengenali situasi-situasi yang berpotensi menjadi masalah dan menimbulkan stres baginya yang menghambat motivasi dan prestasi belajarnya. Disamping itu ia juga dibimbing untuk mendapatkan wawasan yang lebih kaya dan insight akan strategi coping hambatan yang dihadapinya dari literatur yang dibacanya. Proses vicarious learning diharapkan dapat terjadi. Siswa belajar dari pengalaman tokoh dalam bacaan (Herbert \& Kent Dalam Abdullah, 2002; Erford, 2015).

Apabila santri tangguh maka ia tidak mudah stres dan mampu membangun motivasi dan prestasi belajarnya secara optimal. Dipilihnya metode biblioterapi juga karena peneliti belum menemukan kajian biblioterapi untuk meningkatkan ketangguhan akademik remaja belum pada penelitian-penelitian sebelumnya. Atas seluruh penjabaran di atas, peneliti tertarik melakukan penelitian mengenai, efektivitas biblioterapi untuk meningkatkan ketangguhan akademik santri pesantren.

\section{Rumusan Masalah}


Berdasarkan latar belakang penelitian yang dijabarkan diatas, peneliti tertarik untuk melakukan penelitian dengan rumusan masalah: apakah metode biblioterapi efektif untuk meningkatkan ketangguhan akademik santri di pondok pesantren $\mathrm{X}$ ?

\section{METODE PENELITIAN}

Partisipan dalam penelitian ini adalah sepuluh santri pesantren $X$ yang duduk di sekolah menengah pertama kelas VII, di tahun pertama menjalani masa pendidikan di pesantren, dan berusia 11-14 tahun. Partisipan juga menunjukkan hasil pengukuran skor ketangguhan akademik yang berada dalam ketegori rendah. Partisipan juga tergolong santri dengan prestasi akademik dibawah batas ketuntasan minimal. Atas dasar kriteria-kriteria tersebut, metode pengambilan sampel yang digunakan dalam penelitian ini adalah non probability sampling dengan teknik purposive sampling.

Selanjutnya kesepuluh santri tersebut dibagi menjadi dua kelompok secara acak sehingga menjadi lima santri berada dalam kelompok eksperimen dan lima santri dalam kelompok kontrol. Desain penelitian yang digunakan yaitu penelitian eksperimen dengan randomized pretestposttest control group design. Partisipan yang tergolong dalam kelompok eksperimen mendapatkan perlakuan biblioterapi sedangkan kelompok kontrol tidak diberikan perlakuan biblioterapi. Tujuan pemberian perlakuan biblioterapi untuk mengetahui efektivitas biblioterapi untuk meningkatkan ketangguhan akademik santri pesantren X.

Instrumen yang digunakan pada penelitian ini adalah alat ukur ketangguhan akademik yang dikembangkan oleh Benishek dan Lopez (2001). Revisi terbaru alat ukur ini dilakukan pada penelitian Creed, Conlon, dan Dhaliwal (2013), yang menyusun 19 butir pernyataan dalam mengukur 3 dimensi dari ketangguhan akademik, yaitu dimensi komitmen, tantangan, dan kontrol. Peneliti kemudian melakukan adaptasi alat ukur ketangguhan akademik dan menambahkan sebanyak 3 butir kalimat pernyataan tambahan yang disesuaikan dengan karakteristik kehidupan pendidikan seorang santri di pesantren sehingga keseluruhan butir pernyataan alat ukur menjadi 22 butir kalimat pernyataan.

Try out alat ukur dilakukan dengan menyebar kuesioner alat ukur ketangguhan akademik yang telah disusun peneliti pada santri kelas VII pesantren X yang berjumlah 153 anak. Hanya 121 data santri yang kemudian diolah dalam uji reliabilitas alat ukur. Hasil uji reliabilitas melalui perhitungan SPSS menunjukkan hasil $r=0.781$, setelah membuang 3 butir harus dibuang karena koefisien inter item correlation dibawah 0.196 pada level signifikansi 0.05 , sehingga jumlah butir kalimat pernyataan yang tersisa menjadi 19 butir dari jumlah awal 22 butir.

Di antara contoh kalimat pernyataan positif dalam pengukuran ketangguhan akademik pada dimensi komitmen, dalam kalimat positif, "Saya berusaha belajar sebaik mungkin pada setiap pelajaran di sekolah", yang kemudian diberi pilihan penilaian dalam skala interval 1-4. Selain itu juga terdapat kalimat pernyataan dalam kalimat negatif, "Saya merasa terbebani dengan semua aturan kedisiplinan yang berlaku di sekolah". Dengan skala penilaian yang sama, 1-4, tetapi dalam urutan terbalik.

Setelah menentukan kelompok partisipan eksperimen dan kontrol atas dasar hasil pre-test pengukuran dengan instrumen ketangguhan akademik tersebut, dilanjutkan dengan pemberian perlakuan biblioterapi pada kelompok eksperimen. Penerapan biblioterapi didasarkan pada 
langkah-langkah yang dikembangkan oleh Pardeck (1993) menyebutkan bahwa ada empat langkah dalam menerapkan biblioterapi yaitu, tahap identifikasi, seleksi, presentasi, dan followup (dalam Abdullah( 2002); dalam Erford (2015). Identifikasi adalah tahap dimana konselor melakukan identifikasi masalah dan kebutuhan solusi klien.

Tahap selanjutnya yaitu, seleksi buku. Tahap ini konselor memilihkan buku yang sesuai dengan kebutuhan situasi yang dihadapi klien. Jackson (2001) menyampaikan bahwa buku yang dipilih adalah buku yang ditulis dengan bahasa yang dapat dipahami oleh klien dan tokoh-tokoh yang dikisahkan adalah tokoh yang dapat dipercaya. Young (2013) memaparkan bahwa buku yang dipilih sebaiknya berisi nilai-nilai dan tujuan yang sesuai dengan nilai-nilai dan tujuan hidup klien. Atas dasar kriteria-kriteria tersebut diatas peneliti memilih materi bacaan dari dua buku berisi kisah tokoh yang menjalani pengalaman pendidikan di pesantren sebagaimana halnya situasi yang dialami para partisipan penelitian.

Tahap presentasi yaitu tahap yang diisi dengan kegiatan membaca buku. Proses membaca buku dapat dilakukan dalam beberapa cara, yaitu, membaca mandiri, membaca diluar sesi pertemuan, membaca saat pertemuan sesi konseling, yang dilanjutkan dengan kegiatan diskusi bersama mengenai aspek-aspek yang dikisahkan dalam buku. Konselor dapat meminta klien menggaris bawahi poin penting dari materi bacaan. Jackson (2001) memaparkan cara yang dapat dilakukan konselor dalam membantu klien melakukan identifikasi diri lewat kisah tokoh yang dibaca. Beberapa cara tersebut diantaranya, meminta klien menceritakan kembali kisah/materi bacaan yang dibaca (dalam Erford, 2015) .

Tahap akhir biblioterapi yaitu, follow-up. Abdullah (2002) memaparkan bahwa tahap ini diisi dengan kegiatan diskusi antara konselor dengan klien yang mengenai pelajaran yang didapatkan klien dari proses identifikasi diri lewat tokoh kisah dari buku yang dibaca. Jackson (2001) mengungkapkan bahwa klien dapat mengekspresikan pemahamannya lewat kegiatan diskusi, role play, dengan media seni lainnya, ataupun cara kreatif lainnya (dalam Erford, 2015.) Adapun kegiatan biblioterapi yang diterapkan peneliti pada tahap ini dengan kegiatan diskusi dilanjutkan kegiatan membuat kreasi. Setelah membuat kreasi partisipan diminta menuliskan refleksi pemahaman diri pada lembar tugas dari kegiatan biblioterapi. Setelah menyelesaikan semua langkah dalam menerapkan biblioterapi dilakukanlah pengukuran post-test ketangguhan akademik pada partisipan kedua kelompok penelitian.

Adapun prosedur penelitian ini diawali dengan kegiatan observasi tak terstuktur peneliti pada lembaga pesantren $\mathrm{X}$ untuk menemukan fenomena masalah. Peneliti kemudian menetapkan dependent variabel (DV) yang hendak diteliti dan mencari alat ukur variabel. Bersamaan dengan kegiatan tersebut, peneliti mengurus perizinan guna menyelenggarakan penelitian di lembaga pesantren X. Selanjutnya peneliti melakukan adaptasi dan uji reliabilitas alat ukur yang akan digunakan pada populasi partisipan yang berada di pesantren $\mathrm{X}$.

Hasil pengukuran pre-test, sepuluh partisipan masuk kategori kelompok dengan skor ketangguhan rendah. Selanjutnya peneliti membagi kesepuluh partisipan tersebut menjadi dua kelompok penelitian secara acak yaitu, lima partisipan dalam kelompok eksperimen dan lima partisipan dalam kelompok kontrol. Partisipan pada kelompok eksperimen yang mendapatkan perlakuan biblioterapi. Sementara kelompok kontrol tidak mendapat perlakuan biblioterapi, dan mengikuti Kegiatan Belajar Mengajar (KBM) sebagaimana biasanya. Sebelum melaksanakan 
kegiatan biblioterapi, peneliti menyusun rancangan kegiatan biblioterapi untuk meningkatkan ketangguhan akademik santri pesantren.

Selanjutnya peneliti melaksanakan kegiatan sesuai rancangan yang dibuat dengan jadwal pertemuan yang disepakati pihak lembaga juga partisipan dalam 6 pekan pertemuan untuk 11 sesi pertemuan. Kegiatan biblioterapi ditutup dengan pemberian post-test ketangguhan akademik baik pada partisipan kelompok eksperimen maupun kontrol. Pengukuran post-test ketangguhan akademik menggunakan kuesioner yang sama dengan kuesioner pada saat pre-test. Kemudian peneliti mengadakan sesi pertemuan dengan kelompok kontrol untuk menyampaikan ringkasan isi kegiatan intervensi yang telah diterima kelompok eksperimen. Kegiatan penelitian lapangan pun selesai dilaksanakan.

\section{HASIL DAN PEMBAHASAN}

Hasil penelitian menunjukkan biblioterapi tidak efektif untuk meningkatkan ketangguhan akademik santri. Hal ini ditunjukkan pada tabel hasil olah spss uji beda independent sample ttest. Uji beda dengan menggunakan gain score ketangguhan akademik kelompok eksperimen dan kontrol. Hasil pengujian sebagaimana pada tabel berikut.

Tabel 1. Hasil Uji Beda Independent sample t-test

\begin{tabular}{lllllll}
\hline Kelompok & Mean & $\begin{array}{l}\text { Standar } \\
\text { Deviasi }\end{array}$ & F & $\begin{array}{l}\text { Sig } \\
(\mathrm{P})\end{array}$ & $\mathrm{T}$ & $\mathrm{p}$ \\
\hline Kontrol & 3,40 & 5,37 & 0.70 & 0,43 &,- 17 & 0,87 \\
Eksperimen & 2,60 & 8,82 & & & & \\
\hline
\end{tabular}

Berdasarkan tabel 17 di atas, tidak terdapat perbedaan yang signifikan pada skor ketangguhan akademik antara kelompok kontrol dan eksperimen. Hal ini menunjukkan tidak terdapat perbedaan yang berarti terhadap perubahan skor skala pengukuran sikap ketangguhan akademik yang terdiri dari tiga dimensi sikap, yaitu, dimensi sikap komitmen, kontrol diri, dan tantangan, antara kelompok yang mendapat perlakuan biblioterapi (eksperimen) dengan kelompok yang mendapat perlakuan metode lainnya (kontrol). Dengan demikian biblioterapi tidak efektif untuk meningkatkan ketangguhan akademik santri $(\mathrm{t}=-, 17, \mathrm{p}=0,87>0,05)$.

Hasil penelitian tersebut dapat dipengaruhi oleh faktor-faktor berikut. Sebagaimana dipaparkan oleh Gladding dan Gladding (1991) bahwa hal utama yang mendasari biblioterapi ini adalah klien perlu mampu mengidentifikasi diri dengan salah satu karakter dalam buku yang mengalami masalah yang mirip dengan masalah yang dihadapinya. Membaca buku dan menemukan identifikasi dengan karakter tersebut, menjadi momen melepaskan emosi yang menekan, mendapatkan arah yang baru dalam hidup dan mencari cara-cara baru dalam berinteraksi. Hebert dan Kent (2000) menemukan bahwa klien dapat belajar secara vicarious (belajar lewat pengalaman orang lain) bagaimana caranya mengatasi masalah yang dialaminya, dengan merefleksikan diri pada cara karakter tokoh dalam buku dalam mengatasi masalahnya (dalam Abdullah, 2002 ; Erford, 2015).

Nehls (dalam Roberts, 2010) menjelaskan bahwa karakteristik vicarious learning adalah adanya proses active listening dan cara berpikir reflektif, berupaya memahami pokok masalah dengan terlibat aktif dalam situasi belajar. Hal-hal yang tersebut di atas yang mempengaruhi efektifnya penerapan biblioterapi nampak kurang tercapai selama pelaksanaan kegiatan biblioterapi pada 
penelitian ini. Kondisi partisipan yang lelah dan kurang memiliki kesiapan dalam mengikuti kegiatan biblioterapi berpengaruh pada proses vicarious learning yang menjadi sulit terbangun pada partisipan. Partisipan menjadi kurang terdorong untuk terlibat aktif dalam situasi belajar dan diskusi yang dibangun oleh fasilitator.

Pelaksanaan biblioterapi pada partisipan pada pukul 14.00-15.00 WIB mempengaruhi motivasi dan kesiapan partisipan untuk membaca materi bacaan biblioterapi. Hal tersebut karena aktivitas mereka sebagai santri yang sudah dimulai sejak pukul 04.00 pagi menjadikan kondisi mereka saat mengikuti biblioterapi pada siang hari dalam kondisi yang kurang ideal karena cukup lelah dengan kegiatan yang mereka lakukan di pagi hari. Kurangnya kesiapan partisipan dalam mengikuti kegiatan biblioterapi berdampak pada sulitnya fasilitator untuk membangun diskusi yang membahas isi kisah karakter tokoh secara mendalam dan optimal. Kondisi tersebut yang nampak dalam proses biblioterapi pada penelitian ini sebagaimana yang dipaparkan oleh Gladding dan Gladding (1993) bahwa kurang siap partisipan dengan kegiatan biblioterapi berdampak membuat partisipan menjadi defensive, mengabaikan karakter tokoh yang diceritakan dan gagal melakukan identifikasi karakter tokoh yang dikisahkan dalam buku (dalam Abdullah, 2002). Kondisi-kondisi tersebut menjadikan penerapan biblioterapi dalam penelitian ini menjadi tidak efektif untuk meningkatkan ketangguhan akademik santri partisipan dalam kelompok eksperimen.

\section{KESIMPULAN DAN SARAN}

Hasil uji beda skor perolehan pre dan post dari ketangguhan akademik pada kelompok eksperimen menunjukan bahwa tidak terdapat perbedaan skor ketangguhan akademik yang berarti sebelum dan sesudah kegiatan biblioterapi. Dengan demikian biblioterapi yang dilaksanakan dalam penelitian ini tidak cukup efektif untuk meningkatkan ketangguhan akademik.

Saran Praktis bagi partisipan dan santri pada umumnya dalam upaya meningkatkan ketangguhan akademik agar mencapai prestasi belajar yang optimal melalui inti dari biblioterapi diantaranya dengan membuat kelompok membaca sesuai hobi juga dapat dilakukan agar terus mengasah kemampuan berpikir kritis dan reflektif diri melalui diskusi kelompok. Hal tersebut dapat memperluas wawasan dan melatih keterampilan coping diri dalam menghadapi situasi dan kondisi yang dialaminya.

Saran bagi lembaga pesantren X, adalah meningkatkan dan mengoptimalkan peran perpustakaan dalam membangun minat dan kemampuan membaca para santri. Diantara yang dapat dilakukan dengan menambah koleksi dan memperluas khasanah literatur sehingga dapat membantu santri membangun kekayaan wawasan dalam berpikir. Hal ini dapat bermanfaat bagi santri menjadi lebih kaya dalam mencari solusi-solusi yang baik untuk mengatasi permasalahan yang dihadapinya.

Di samping itu, program literasi yang sudah ada terus dikembangkan dan disempurnakan dalam bentuk kegiatan kelompok-kelompok membaca dengan pendampingan agar terbangun diskusi antar anggota kelompok yang terarah dengan manfaat yang optimal. Kegiatan tersebut dapat disertai kegiatan apresiasi hasil membaca mereka dengan karya-karya hasil baca santri yang bagus dan inspiratif sehingga memberikan pengalaman yang positif bagi yang membuat dan mendorong minat membaca santri lainnya. 
Dalam membantu membangun ketangguhan akademik santri terutama pada dimensi kontrol, diharapkan sistem pendidikan di pesantren dapat lebih mengembangkan kegiatan yang memberikan pengalaman-pengalaman yang positif bagi pengembangan kemampuan diri santri. Pengalaman positif yang dialami anak akan membuat evaluasi positif santri terhadap pendidikan yang dijalaninya di pesantren yang dapat menambah kepercayaan diri akan kemampuannya dalam menyelesaikan tugas-tugas yang kemudian dapat meningkatkan ketangguhan akademiknya. Diantara yang dapat dikembangkan pesantren adalah bentuk kegiatan apresiasi pada materi-materi pembelajaran di pesantren seperti dalam bidang bahasa, sains, ataupun keagamaan. Di samping itu, diharapkan lembaga dapat mengadakan pelatihan yang dapat melatih dan meningkatkan ketrampilan belajar santri sehingga dapat membantu santri untuk mengatasi dan memenuhi tuntutan akademik lebih baikl lagi, diantara yang dapat dikembangkan, pelatihan menghafal qur'an yang baik dan benar dengan manajemen waktu yang efisien agar membantu santri memenuhi setoran hafalan lebih optimal.

Saran bagi penelitian selanjutnya mengenai efektivitas Biblioterapi adalah: (a) mengkaji tingkat kelelahan para santri, sehingga pelaksanaan biblioterapi dapat ditempatkan pada waktu yang lebih tepat; (b) mempersiapkan materi pendahuluan yang meningkatkan motivasi dan kesiapan santri untuk mengikuti program biblioterapi; (c) meningkatkan kemampuan dan minta baca Bahasa Indonesia pada para santri, untuk meningkatkan kesiapan Santri dalam mengikuti Biblioterapi.

Sebelum menerapkan metode biblioterapi disarankan dilaksanakan percobaan untuk mengetahui seberapa besar pengaruh buku-buku tertentu dan pertanyaan-pertanyaan dalam diskusi yang efektif sehingga dapat dilakukan replikasi dan penelitian lanjutan. Dengan percobaan tersebut dapat membantu konselor atau fasilitator memberikan materi bacaan yang tepat sesuai kebutuhan partisipan sehingga memberikan manfaat yang efektif. Disarankan juga pada penelitian selanjutnya dilakukan pada jumlah partisipan yang lebih banyak sehingga mendorong proses diskusi dalam kelompok lebih aktif dan proses vicarous learning dapat berjalan optimal. Dalam menjalankan biblioterapi disarankan dikembangkan dalam bentuk kegiatan yang lebih menyenangkan dan rileks dengan waktu yang lebih lama sehingga emosi partisipan yang terbangun lebih positif dalam mengikuti biblioterapi sehingga proses refleksi diri dan pengambilan insight bagi peningkatan coping partisipan dapat tercapai dengan efektif dan optimal.

Hal lain yang juga perlu diperhatikan yaitu saat proses pengukuran ketangguhan akademik atau variabel penelitian perlu mempertimbangkan kenyamanan dan ketenangan partisipan selama mengisi kuesioner sehingga data yang diberikan partisipan merupakan evaluasi diri yang sebaikbaiknya atas proses yang dijalaninya.

\section{Ucapan Terima Kasih (Acknowledgement)}

Peneliti mengucapkan terimakasih yang sebesar-besarnya kepada pimpinan pesantren X, terutama pimpinan SMPIT pesantren $\mathrm{X}$, yang telah memberikan kesempatan pelaksanaan penelitian dan penerapan biblioterapi dari awal hingga selesai. Terimakasih juga peneliti haturkan kepada kepada santri kelas 7 SMPIT di Pesantren X yang telah berpartisipasi pada penelitian ini dari mulai pengambilan data awal, penerapan biblioterapi, hingga pengambilan data akhir. Sebagai tambahan, peneliti juga mengucapkan terimakasih kepada para guru, yang telah membantu dalam pelaksanaan penelitian ini. 


\section{REFERENSI}

Ahmadi, A., Zainalipour, H. \& Rahmani, M. (2013). Studying the role of academic hardiness in academic achievement of students of Islamic Azad University, Bandar Abbas Branch. Journal of Life Science and Biomedicine, 3(6), 418-423.

Abdullah \& Hayati, M. (2002). Bibliotherapy. ERIC Digest. Bloomington, IN: ERIC Clearinghouse on Reading, English, and Communication. (ERIC Document Reproduction Service No. ED470712)

Ali, M. A. (1986). Pondok Pesantren dalam Sistem Pendidikan Nasional. Pusat Studi Inter disipliner Tentang Islam. Surabaya: IAIN Sunan Ampel.

Benishek, L. A., \& Lopez, F. G. (2001). Development and Initial Validation of Measure of Academic Hardiness. Journal of Career Assessment, 9, 333-352.

Benishek, L. A., Feldman, J. M., Shipo, S. D., \& Lopez, F. G. (2005). Development and Evaluation of the Revised Academic Hardiness Scale. Journal of Career Assessment, 13(1), 59-76.

Creed, P. A., Conlon, E. G., Dhaliwal, K. (2013). Revisiting the Academic Hardiness Scale: Revision and Revalidation. Journal of Career Assessment, 21(4), 537-554.

Cole, M. S., Field, H. S., \& Harris, S. G. (2004). Student Learning Motivation and Psychological Hardiness: Interactive Effects on Students' Reaction to a Management Class. Academy of Management Learning and Education, 3(1), 64-85.

Erford, B. T. (2015). 40 Techniques Every Counselor Should Know. 2nd Ed. USA: Pearson Education Inc.

Hystad, S. W., Eid, J., Laberg, J.C., \& Johnsen, B. H. (2009). Academic Stress and Health: Exploring the Moderating Role of Personality Hardiness. Scandinavian Journal of Educational Research, 53(5), 421-429.

Hannah, T., E., \& Morrissey, C. (2005). Correlates of Psychological Hardiness in Canadian Adolescents. The Journal of Social Psychology. 127I(4), 339-344.

Heath, M. A., Sheen, D., Leavy, D., Young, E., \& Money, K. (2005). Bibliotherapy. A Resource To Facilitate Emotional Healing and Growth. School Psychology International. 26(5), 563 580.

Hastono, SP. 2001. Analisis Data. Jakarta: FKM-UI Harvey, P. (2010). Bibliotherapy Use By Welfare Teams In Secondary Colleges.

Hebert, T. P. \& Kent, R. (2000). Nurturing social and emotional development in gifted teenagers through young adult literature. Roeper Review, 22(3), p167-171.

Australian Journal of Teacher Education, 35(5). Jacob, J., \& De Guzman, R. (2016). Effectiveness of taking in the good based bibliotherapy intervention program among depressed Filipino female adolescents. Asian Journal of Psychiatry.

Lucas, C., V., \& Soares, L. (2013). Bibliotherapy: A tool to promote children's psychological well-being. Journal of Poetry Therapy, 26, 137-147.

Martin, A. J., Papworth, B., Ginns, P., Liem, G. A. D. (2014). Boarding School, Academic Motivation and Engagement, and Psychological Well-Being: A Large-Scale Investigation. American Educational Research Journal, 51(5), 1007-1049.

Montgomery, P., Maunders, K., (2015). The Effectiveness of Creative Bibliotherapy for Internalizing, Externalizing, and Prosocial Behaviors in Children: A systematic review. Children and Youth Review, 55, 37-47.

Muto, T., Hayes, S. C., Jeffcoat, T., (2011). The Effectiveness of Acceptance and Commitment Therapy Bibliotherapy for Enhancing the Psychological Health of Japanese College Students Living Abroad. Behavior Therapy, 42, 323-335. 
Mujamil, Qomar. 2002. Pesantren dari Transformasi Metode Menuju Demokrasi Instuisi. Jakarta: Erlangga

Maddi, S. R. (2006). Hardiness: The courage to go from stresses. The Journal of Positive Psychology, 1(3), 160-168.

Maddi, S. R., (1999) The Personality Construct of Hardiness: I. Effects on Experiencing, Coping, and Strain. Consulting Psychology Journal, 51(2), 83-94.

Nisfiannoor, M. (2013). Pendekatan Statistika Modern : Aplikasi dengan software SPSS dan Eviews. Jakarta: Penerbit Universitas Trisakti.

Roberts, D., (2010). Vicarious Learning : A review of the literature. Nurse Education in Practice, 10, 13-16.

Santoso, S. 2001. Buku Latihan Statistik Non Parametrik. Jakarta: Gramedia

Santoso, S. 1999. SPSS Mengolah Data Statistik Secara Profesional. Jakarta: Gramedia.

Sheard, M., (2009). Hardiness Commitment, Gender, and Age Differentiate University Academic Performance. British Journal of Educational Psychology, 79, 189-204.

Sheard, M.,\& Golby, J., (2007). Hardiness and undergraduate academic study: The moderating role of commitment. Personality and Individual Differences, 43, 579-588.

Shivagunde, S. Kulkarni, V. V.(2012). School Adjustment And Its Relationship With Academic Achievement Among Tribal Students. IJRDMS, 6 (1).

Santrock, J.W. (2013). Children. Thirteenth Edition. New York: McGraw-Hill.

Tafsir, A, dkk.( 2004). Cakrawala Pemikiran Pendidikan Islam. Bandung: Mimbar Pustaka.

Wisudawati, W. N., Sahrani, R., \& Hastuti, R. (2017). Efektivitas Pelatihan Ketangguhan (Hardiness) Untuk Meningkatkan Motivasi Berprestasi Akademik Siswa Atlet. Provitae Jurnal Psikologi Pendidikan, 10(2), 1 - 2. 